\title{
Blood Loss and Massive Transfusion in Patients Undergoing Major Oncological Surgery: What Do We Know?
}

\author{
Juan P. Cata and Vijaya Gottumukkala \\ Department of Anesthesiology and Perioperative Medicine, The University of Texas MD Anderson Cancer Center, \\ 1400 Holcombe Boulevard, Unit 409, Houston, TX 77030, USA \\ Correspondence should be addressed to Juan P. Cata, jcata@mdanderson.org
}

Received 5 February 2012; Accepted 4 March 2012

Academic Editors: C. Motamed, D. E. Selander, S. J. Verbrugge, and C.-T. Wu

Copyright ( 92012 J. P. Cata and V. Gottumukkala. This is an open access article distributed under the Creative Commons Attribution License, which permits unrestricted use, distribution, and reproduction in any medium, provided the original work is properly cited.

\begin{abstract}
Patients with solid malignancies who were not candidates for tumor resections in the past are now presenting for extensive oncological resections. Cancer patients are at risk for thromboembolic complications due to an underlying hypercoagulable state; however, some patients may have an increased risk for bleeding due to the effects of chemotherapy, the administration of anticoagulant drugs, tumor-related fibrinolysis, tumor location, tumor vascularity, and extent of disease. A common potential complication of all complex oncological surgeries is massive intra- and postoperative hemorrhage and the subsequent risk for massive blood transfusion. This can be anticipated or unexpected. Several surgical and anesthesia interventions including preoperative tumor embolization, major vessel occlusion, hemodynamic manipulation, and perioperative antifibrinolytic therapy have been used to prevent or control blood loss with varying success. The exact incidence of massive blood transfusion in oncological surgery is largely unknown and/or underreported. The current literature mostly consists of purely descriptive observational studies. Thus, recommendation regarding specific perioperative intervention cannot be made at this point, and more research is warranted.
\end{abstract}

\section{Introduction}

Surgical oncology, perioperative medicine, and anesthesia for oncological care have been evolving over the last four decades. Aggressive chemoradiation regimens, newer and bolder surgical techniques, effective anesthesia modalities, and impressive intensive care medicine strategies have facilitated tumor resections, which were considered difficult or unadvisable in the past [1-4]. Thus, patients with large hypervascularized tumors or cancers encasing major blood vessels are now considered acceptable surgical candidates [4]. One of the consequences of performing surgery in such patients is the risk of significant intra- and postoperative blood loss. When bleeding occurs unexpectedly and uncontrollably in the perioperative period, there is a sharp increase in mortality $[5,6]$.

It has been suggested that patients with cancer are more likely to be transfused with blood products than noncancer patients [7]. Moreover, an unknown percentage of these patients are at risk for massive blood transfusion, which is commonly defined as the transfusion of more that 10 units of packed red blood cells in a 24-hour period [8]. Massive blood transfusions during oncological surgery can be anticipated or unexpected. In the former situation, since anesthesiologists, surgeons, and the blood bank services are aware of the possibility of massive blood transfusion, precautions are taken to minimize blood loss and maximize efficiency of blood product availability and administration. Several authors have investigated the use of controlled hypotension, preoperative tumor embolization, temporary aortic occlusion, and the administration of antifibrinolytic therapy to decrease blood loss and subsequent blood transfusions [7, 9-14]. Unanticipated cases of massive blood loss necessitate immediate control of surgical bleeding and measures to promptly evaluate the hemostatic defect. Managing this critical event effectively requires understanding the physiology of the coagulant and fibrinolytic systems, expeditiously managing the metabolic and hemodynamic milieu, maintaining normothermia, and coordinating care with the blood bank services to assure appropriate blood product supply in a timely manner. 
In the present manuscript, we will review the literature on massive blood loss and massive blood transfusion during the perioperative period of major oncologic surgery.

\section{Why Cancer Patients May Bleed Excessively during Surgery?}

Most bleeding associated with surgical procedures is due to poor surgical hemostasis, also known as "silk deficiency" [15]. However, patients with cancer may also have other factors that contribute to significant perioperative bleeding.

It is well known that hematological and nonhematological malignancies activate the blood coagulation system through the release of procoagulant factors, activation of the antifibrinolytic pathways, and the creation of an imbalance between pro- and antiinflammatory cytokines, which favor the production of peripheral clots in the majority of patients $[16,17]$. This procoagulant state may also continue into the postoperative period [18].

However, some patients may actually have an increased tendency to bleed excessively due to the effects of chemotherapy agents (anemia, thrombocytopenia, and endothelial system dysfunction), the administration of anticoagulant drugs (warfarin and unfractionated or low-molecular-weight heparin) to prevent the formation of deep vein thrombosis, increased fibrinolysis as in men with prostate cancer, and certain metastatic diseases $[19,20]$. The incidence of preoperative thrombocytopenia is rare in patients having nonemergent oncological surgery. For example, thrombocytopenia defined as platelet count lower than 100,000 can be found in only $1 \%$ of the patients undergoing liver resection for primary or metastatic liver tumors [21]. It is well known that although patients with liquid tumors may have thrombocytopenia, they do not always demonstrate a clinical hemostatic defect. If such a patient presents for a surgical procedure, perioperative care involving excessive bleeding should be based on an objective assessment of the hemostatic function (standard and advanced hemostatic function tests) and the administration of appropriate agents (pharmacological and blood products) to correct the defect rather than a regimen-based transfusion practice to meet specific laboratory goals [22].

Patients with cancer are at risk for significant bleeding due to tumor-related factors such as proximity or invasion of major vascular structures or hypervascularization of the cancerous tissue itself $[17,18]$. Lastly, it is also well known that major tissue trauma as observed in extensive oncological surgery may alter the functional equilibrium between soluble plasma fractions, erythrocytes, leukocytes, platelets, and the fibrinolytic system. This imbalance in hemostatic function may contribute to a significant coagulopathy, especially in conditions such as prolonged hypotension, hypoxemia, ischemia, massive bleeding, and acidemia. Massive bleeding and prolonged hypotension have been associated with thrombocytopenia, abnormal clotting times, and low circulating levels of fibrinogen, suggesting a clinical condition of consumptive coagulopathy $[23,24]$. Hypoxemia, which may be seen during thoracic oncologic surgery (one lung ventilation) or after excessive fluid resuscitation, activates the fibrinolytic system directly via effects on endothelial cells and indirectly by the release of catecholamines $[25,26]$. Ischemia as seen during a prolonged period of hypotension or long tourniquet times (during limb surgery) is also known to induce fibrinolysis through the systemic release of tissue plasminogen activator (tPA) [27]. Metabolic acidemia as encountered during hemorrhagic shock and/or excessive resuscitation with saline solution may also have significant effects on the coagulation system. This phenomenon has been shown in experiments in which hydrochloric acid $(\mathrm{HCl})$ added to blood obtained from patients and titrated to a $\mathrm{pH}$ of 7.0 caused inhibition of thrombin propagation and a decrease in the activity of the Xa/ $\mathrm{Va}$, which was observed as prolonged clotting times on standard coagulation tests and abnormal patterns on thromboelastography [28, 29]. Finally, dilutional thrombocytopenia, especially after massive blood transfusion and excessive administration of isotonic crystalloid solutions, is a common cause of perioperative coagulopathy [30].

In summary, solid tumor cancer surgery is usually associated with a predominant hypercoagulable state in the perioperative period; however, after extensive (tissue trauma) surgery, excessive volume replacement, hypothermia, hypotension, or acidemia, a shift towards dilutional coagulopathy with or without consumptive coagulation disorder can be expected.

\section{Oncologic Surgery Procedures at Risk for Massive Blood Transfusions}

3.1. Nephrectomy with Inferior Venous Cava Thrombectomy. Renal cancer has an incidence of about $3.1 \%$ in the adult population [31]. Renal cell carcinomas (RCCs) have a tendency to invade the venous system: first into the renal vein and then advancing into the inferior venous cava (IVC) as the disease progresses. RCC extension into the IVC has been reported in between $4 \%$ and $19 \%$ of the patients [32, 33]. According to the extent of their invasion into the IVC system, these tumors are classified into 4 categories, level I: tumor thrombus extending in the renal vein or for less than $2 \mathrm{~cm}$ into the infrahepatic segment of the IVC; level II: tumor thrombus extending into the IVC to below the hepatic vein; level III: tumor thrombus extending into the suprahepatic segment of the vena cava; level IV: those progressing into the right atrium [34].

Surgery remains one of the main therapeutic modalities for patients with localized RCC as well as in those with invasion of the renal vein and/or the IVC system. The degree of surgical aggressiveness depends on the level of the thrombus extension. Radical nephrectomy with infra- or supradiaphragmatic IVC thrombectomy is the surgical options for patients with IVC tumor thrombus [35]. The surgical approach for those patients with RCC extension into the liver may vary and may involve a nephrectomy combined with a partial liver resection [36]. Concomitant splenectomy may also be required in about $2 \%$ to $8 \%$ of these patients [37].

Surgical approaches for caval thrombectomy have a high risk of significant blood loss and the subsequent need for a massive blood transfusion. Reported estimated blood loss 
TABLE 1: Type of surgery, blood loss, and blood transfusion.

\begin{tabular}{lcc}
\hline Type of surgery & Range of blood loss (cc) & Range of PRBCs units \\
\hline Spine tumors [38-43] & $400-12,100$ & $2-10$ \\
Sacral tumors [44-46] & $3,000-37,000$ & $0-43$ \\
Hemipelvectomy [47-50] & $400-12,100$ & $0-134$ \\
Total pelvic exenterations [47-50] & $900-9,500$ & $0-18$ \\
Nephrectomy with IVC embolectomy [37, 51-55] & $200-16,000$ & $0-91$ \\
Liver and multivisceral resection [12,56-62] & $200->5,000$ & $0-44$ \\
Extrapleural pneumonectomies [63-65] & $900-65,00$ & $0-18$ \\
\hline
\end{tabular}

Table 1 illustrates ranges of blood losses and PRBCs of transfused units reported in the literature.

ranges from $200 \mathrm{cc}$ to $16,000 \mathrm{cc}$ and mainly depends on the patient's age, tumor size, the level of vascular invasiveness, and factors inherent to the surgical procedures itself such as total versus partial nephrectomy, duration of surgery, preoperative renal artery embolization, use of traditional or minimal invasive cardiopulmonary bypass, and surgeon experience [36, 37, 51-54, 66-68]. Two observational studies demonstrated an increased rate of blood loss in patients with a level III or IV caval tumor thrombus, and in whom cardiopulmonary bypass with or without hypothermic arrest was used during the thrombectomy $[69,70]$. Notably, the use of hypothermia increases the risk of coagulopathy and subsequent bleeding [68].

Fifty to 100 percent of the patients undergoing radical nephrectomies followed by IVC thrombectomy are transfused with packed red cell (PRBCs) $[68,71]$; however, the exact incidence of patients having massive blood transfusion is unknown. The reported number of PRBC units transfused varies significantly (from 0 to 91), as does the time period over which the transfusions are administered in the perioperative period [37, 51-55] (Table 1). This is due to the fact that some authors have reported "perioperative" blood transfusions without clear specifications about timing parameters, while others have only published the number of units administered during the intraoperative and postoperative periods or during intensive care unit admission.

Collectively, nephrectomies in association with vascular resection and reconstruction procedures have an increased risk of blood loss and perioperative blood transfusions. The anesthesiologist participating in those procedures should be aware of the risks of extensive hemorrhage and take all necessary measures to minimize the onset of coagulopathies and blood loss, mainly in tumors with level III/IV extension and in those that extend to adjacent organs.

\subsection{Extrapleural Pneumonectomy for Malignant Pleural Meso-} thelioma. Malignant pleural mesothelioma (MPM) is a rare and highly invasive cancer that originates in the pleural surface $(90 \%)$ or in the extrapleural region (10\%). Radiation, chemotherapy, and surgery, usually used in combination, are preferred treatment options for MPM. However, surgery is associated with a high morbidity $(60-63 \%)$ and mortality $(6.75-14 \%)[63,72,73]$.

Extrapleural pneumonectomy (EPP) has been performed for more than four decades in patients with MPM. One of the potential intraoperative complications of EPP is hemorrhage, which is associated with a high rate of perioperative transfusions (approximately 90\%) [72, 74]. Surgeryassociated hemorrhage complicates the postoperative period, frequently requiring reoperation for control of surgical bleeding [72, 73]. More importantly, the administration of PRBCs is a risk factor for the development of postoperative complications and poor survival [63]. Investigators from our institution studied the role of aprotinin in intraoperative blood loss in patients with mesothelioma undergoing extrapleural pneumonectomy. Despite the trial being interrupted due to withdrawal of aprotinin from the market by the manufacturer, the authors reported that aprotinin decreased blood loss compared to placebo [64] (Table 2).

The exact incidence of massive blood transfusion is also largely unknown for EPP, but two observational studies indicated that approximately $10 \%$ of the patients who underwent EPP received 10 or more units of PRBCs postoperatively, and $16 \%$ of the patients received nonPRBC products perioperatively $[63,65]$ (Table 1 ).

In summary, EPP for MPM is an aggressive surgical modality, which is associated with significant morbidity and mortality. Those participating in the anesthesia and postoperative care of these patients should be conscious of the possibility of massive bleeding and blood transfusions along with a high rate of re-operations.

3.3. Hemipelvectomy for Sarcomas or Metastatic Disease. Hemipelvectomies are surgical procedures that involve the removal of the entire hemipelvis or affected hemipelvis (partial hemipelvectomy) only. The procedure may also involve resection of the ipsilateral lower extremity (external hemipelvectomy or hind-quarter amputation) or a limb sparing procedure (internal hemipelvectomy) [75]. Postoperative mortality varies from 0 to $8 \%$ [76-84]. As expected, intraoperative hemorrhage can be significant during these procedures with reported blood loss ranging from $400 \mathrm{cc}$ to $12,100 \mathrm{cc}[80,82,83,85-89]$.

Blood transfusions are almost always required in the perioperative period of hemipelvectomies; however, the literature is still unclear about the exact rate of massive blood transfusion. A retrospective study of 160 hemipelvectomies reported that the average number of units transfused intraoperatively and during the first 2 days after surgery was 13.4 (range 0-139) units. Another observational study reported 
TABLE 2: Perioperative interventions targeted to reduce blood loss during major oncological surgery.

\begin{tabular}{lll}
\hline Type of surgery & Anesthetic interventions & Surgical interventions \\
\hline Spine tumors & $\begin{array}{l}\text { Antifibrinolytics } \\
\text { Controlled hypotension* }\end{array}$ & $\begin{array}{l}\text { Surgical hemostasis } \\
\text { Preoperative tumor embolization }\end{array}$ \\
\hline Sacral tumors & Antifibrinolytics & $\begin{array}{l}\text { Surgical hemostasis } \\
\text { Preoperative tumor embolization } \\
\text { Aortic balloon occlusion-Iliac artery ligation }\end{array}$ \\
\hline Hemipelvectomy & & Surgical hemostasis \\
& Antifibrinolytics & Vascular control \\
Nephrectomy with IVC embolectomy & & Surgical hemostasis \\
& Antifibrinolytics & Correction of hypothermia after CPB \\
\hline Liver and multivisceral resection & CVP $<5$ cm $\mathrm{H}_{2} \mathrm{O}^{* *}$ & $\begin{array}{l}\text { Surgical hemostasis } \\
\text { Preoperative tumor embolization }\end{array}$ \\
\hline Extrapleural pneumonectomies & Antifibrinolytics & Vascular control \\
\hline
\end{tabular}

* Controlled hypotension has fallen in disfavor of many anesthesiologists due to its possible association with postoperative visual loss. $* *$ This practice has also been questioned due to the poor correlation between central venous pressure and central volume status.

a median transfusion rate of 7 PRBC (range 0-44) units perioperatively [90]. The intra- and postoperative blood transfusion requirements appear to be related to the type and extension of surgical reconstruction. For instance, in those procedures where pelvic stability was maintained, the average number of units transfused was 5; in sharp contrast, 17 units were administered to those patients in whom pelvic stability was not the surgical goal [91].

Total pelvic exenterations (TPEs) defined as the removal of all pelvic organs, including the rectum, bladder, and reproductive organs, have traditionally been performed as curative or palliative surgery in patients with locally advanced primary or recurrent pelvic malignancy [92]. TPEs are associated with significant perioperative morbidity $(38.4 \%-70 \%)$ and a reported mortality rate lower than $5 \%$ in recent publications [47, 48, 93-98].

Despite recent surgical advances, significant blood loss during and after TPEs is still frequent. The rate of transfusion has been reported to be as high as $82 \%$ [48]. Several reports demonstrate that the estimated blood loss ranges between $900 \mathrm{cc}$ and 9,500 $\mathrm{cc}$ (Table 1). However, not all studies report the amount of PRBCs transfused [47-50]. From those studies that have reported the amount of blood transfused, it can be concluded that the number of units PRBCs transfused ranges from zero to 18 [50]. Hence, an unknown number of patients are still receiving massive blood transfusions.

Collectively, a large number of patients undergoing extensive pelvic oncological surgeries are transfused with blood products in the perioperative period, some in large quantities. Thus, anesthesiologists should be prepared to face the clinical challenges associated with massive blood transfusions.

3.4. Liver Resections and Combined Multivisceral Oncologic Surgery. Hepatocellular carcinoma (HCC) is the third most common malignancy of the gastrointestinal tract after colorectal and pancreatic cancer [31]. However, most common tumors of the liver remain metastatic, generally from distant areas of the gastrointestinal tract. The curative therapies available for HCC and metastatic liver diseases include ablative surgery, liver resection, and liver transplantation. Liver resection procedures may involve localized tumorectomies, wedge resection, left or right trisectionectomies, bisegmentectomies, and left or right hepatectomies. Complex resections requiring total vascular exclusions, tumor thrombectomies, and venous-venous bypass are not uncommon in patients with vascular tumor invasion of the portal vein or IVC [99].

The overall rates of morbidity and mortality in patients undergoing complex liver resection are less than $40 \%$ and $10 \%$, respectively $[56-58,100,101]$. Blood loss still remains a significant concern after liver resection with approximately $33 \%, 35 \%$, and $37 \%$ of the patients having a blood loss higher than $5,000 \mathrm{cc}, 2,000 \mathrm{cc}$, and $1,000 \mathrm{cc}$, respectively [58, 102, 103]. The largest observational study to date reported an average estimated blood loss of $871 \mathrm{cc}$ [21]. Understandably, hemorrhage and blood transfusion during liver resections have an important impact on postoperative morbidity and mortality $[21,102,104]$. For instance, blood loss higher than $800 \mathrm{cc}$ is an independent risk factor (odd ratio 1.907) for postoperative morbidity after liver resection [57]. Katz et al. have also reported that estimated blood loss of more than $1 \mathrm{~L}$ was an independent predictor of overall survival (odds ratio -2.2 ), recurrence free survival (odds ratio -1.7 ), and disease-specific survival (odds ratio -2.3) [103]. Moreover, the authors described a "dose-response" relationship between estimated blood loss and disease-specific survival [103].

Anesthetic and surgical techniques have evolved to decrease intraoperative blood loss and develop conservative strategies for transfusion thresholds [59, 105-107]. For instance, the risk of significant intraoperative and postoperative bleeding increases during open complex liver resections as compared to laparoscopic resection. Ker et al. reported that the mean blood loss during laparoscopic resections was $138 \mathrm{cc}$ versus $1174 \mathrm{cc}$ in the open resections [108]. Another factor associated with blood loss is the type of liver resection; 
those involving 3 or more segments are associated with significantly more bleeding (odd ratio 3.035) [59]. Bleeding from the middle hepatic vein also appears to be a risk factor for massive bleeding during liver resection [102]. Thus, vascular control is essential in large and complex resections. Of the several techniques described to minimize blood loss, most are equally effective $[109,110]$.

The pressure within the hepatic sinusoids is considered a predictive factor for intraoperative blood loss. This notion was supported by an early study by Jones et al. who demonstrated that maintaining central venous pressures lower than $5 \mathrm{~cm}$ of water was associated with significantly less bleeding (median $200 \mathrm{cc}$ ) compared to a pressure higher than $5 \mathrm{~cm}$ of water (median blood loss 1,000 cc) [12] (Table 2). However, our own experience indicates that open liver resections can be safely done without central venous pressure monitoring. Other anesthetic maneuvers helpful in reducing blood loss during liver resections include volume restriction prior to specimen resection, reverse Trendelenburg position, epidural analgesia, and systemic infusion of nitroglycerin. Using a combination of epidural blockade and systemic nitroglycerine infusion, Rees et al. reported a perioperative morbidity and mortality of $10 \%$ and $0.7 \%$, respectively [111]. Antifibrinolytics have also been used to decrease blood loss and transfusion during liver surgery, but results have been controversial [13]. In a randomized controlled trial, $\mathrm{Wu}$ and collaborators demonstrated that tranexamic acid reduced blood loss and transfusion in patients undergoing liver tumor resections [14]. Similar results were also reported in another randomized controlled trial in which patients were treated with either aprotinin or placebo [112]. Unfortunately, the clinical use of aprotinin has been questioned due to an increased incidence of renal failure, stroke, and myocardial infarction; aprotinin has since been withdrawn from the US market [113].

The rate and amount of PRBCs transfused in patients undergoing liver resections ranges between $8.7 \%$ and $85.7 \%$ and from 0 to 24 units, respectively [12, 56-60]. In a large series of patients, Katz et al. reported that only $18 \%$ of patients received blood transfusion [103]. The rate of postoperative transfusion has been reported to be as high as $24 \%$ with a reoperation rate from bleeding of $0.4 \%$ to $5.8 \%[114,115]$. As with other surgical oncological procedures, the actual rate of massive blood transfusion intra- and/or postoperatively is largely unknown or underreported. However, an observation study by McCall showed that the rate of massive blood transfusion defined as 10 or more units was $1.7 \%$ in liver resections.

Interestingly, the use of fresh frozen plasma has been reported to be as high as $100 \%$ during liver resection with $13 \%$ of these patients receiving four or more units $[21,58]$. The largest percentage (40\%) of fresh frozen plasma transfused in the perioperative period of liver resection occurs within the first 48 hours [115]. However, the routine administration of this blood product is not justified during routine liver resections, except in cases of significant coagulopathy [58].

Multivisceral operations are usually performed on patients with locally advanced pancreatic cancer, gastric cancer, or retroperitoneal sarcomas in order to achieve negative resection margins and thus a potential cure $[116,117]$. The most common of these surgeries is perhaps the Whipple procedure or duodenal pancreatectomy. Sometimes these procedures also involve total pancreatic resection with venous and arterial vascular dissection and reconstruction followed by liver resections due to metastatic disease [118-120]. Other procedures include gastrectomies with resection of adjacent organs such as spleen, gallbladder, liver, and small and large bowel [61].

As expected, multivisceral operations may be associated with significant risk of bleeding and blood transfusions. The blood loss in these procedures ranges from $300 \mathrm{cc}$ to $5,000 \mathrm{cc}[117,121]$. In contrast to liver resection, most blood transfusions in multivisceral procedures are usually administered intraoperatively, and as expected, extensive procedures involving additional organs/structure are associated with the largest number of transfusions (0-44 units) compared to palliative procedures ( $0-15$ units) or standard resections ( 0 35 units) [61, 62].

In summary, liver and multivisceral resections are among the most common oncological procedures in which massive bleeding and transfusion may occur intra- or postoperatively. More importantly, blood loss and transfusion of blood products have a significant impact on postoperative morbidity and mortality.

3.5. Oncological Spine and Sacral Surgery. Several different surgical procedures are performed for the treatment of metastatic spine tumors; they include combined anterior-posterior vertebrectomy, multisegment vertebral resection, and spinal instrumentation and fusion $[38,122-124]$. The overall morbidity of these procedures ranges from $14.3 \%$ to $36 \%$ $[39-41,125]$. Major blood loss is also a serious concern during extensive spine procedures, and a particular challenge is the resection of spinal metastasis from renal cell carcinomas or other hypervascularized tumors [126, 127].

Different observational studies have reported an average blood loss ranging from $1,360 \mathrm{cc}$ to $3,145 \mathrm{cc}$ during corpectomies or en bloc tumorectomies of the thoracic or cervicothoracic region. However, massive blood loss has also been reported with maximum blood losses of 21,000 cc [3843] (Table 1). Combined anterior-posterior thoracic corpectomies are associated with a higher blood loss than anterior or posterior only approaches [41]. The rate of transfusion in these procedures varies widely. However, most studies report that the rate ranges from $17 \%$ to $70 \%$ [43]. The median number of PRBC units transfused during lumbar surgery for metastatic disease is 2 units; however, an unknown number of patients still receive more than 10 units of packed red cells [42].

Several pharmacological and nonpharmacological interventions have been used in an attempt to reduce blood loss during surgery for spinal tumors. Some authors have recommended preoperative embolization of spinal metastasis to reduce intraoperative blood loss $[9,10]$. Intraoperative controlled hypotension was commonly implemented in the past to diminish blood loss; however, this technique has been questioned due to the risk of postoperative visual loss in long 
and complex spine procedures [128]. Antifibrinolytic therapy including aprotinin, tranexamic acid, and epsilonaminocaproic acid has been shown to decrease blood loss in total knee replacements, scoliosis surgery, and cardiac surgery [129-131]. Bednar et al. reported their experience using tranexamic acid to minimize operative blood loss during a single-surgeon intralesional tumor excision and instrumentation. Although they found a reduction in blood loss with tranexamic acid, the findings of their retrospective review were not statistically significant [132] (Table 2).

Surgical procedures for resection of primary or metastatic sacral tumors are an effective therapeutic option for long-term disease control and cure [133]. Morbidity after sacral tumor resection remains high $[44,134]$. In a large series of patients, Fourney et al. reported a 30-day complication rate of $61 \%$. Unfortunately, significant intra- and postoperative blood loss (due to anatomic characteristics of the sacral region and the size of the tumors) is a common complication with average blood loss estimated between $2,922 \mathrm{cc}$ and $6,300 \mathrm{cc}[45,46,135]$. Remarkably, almost $40 \%$ of the patients had a blood loss greater than $3,000 \mathrm{cc}$ with a maximum blood loss of $37,000 \mathrm{cc}[44,45]$. Risk factors associated with an excessive blood loss are hypervascularity (odds ratio 2.281), tumor location at or cephalad to S2 region (odds ratio 3.84), and tumor volume greater than $200 \mathrm{~cm}^{3}$ (odds ratio 3.381) $[45,136]$. Different pre- and intraoperative interventions have been described to reduce bleeding and related morbidity. A few authors have successfully utilized aortic balloon occlusion to avoid significant bleeding [46, 137, 138]. Others have reported encouraging results with preoperative tumor embolization, ligation of both internal iliac vessels, and staged surgery [139-141].

As expected, transfusion of PRBCs and other blood products is common during sacral surgery. Two retrospective studies including 19 and 24 patients reported that the average number of PRBCs transfused intraoperatively was 10.2 units and 11.5 units, respectively, with a maximum amount of 43 transfused units in one of the studies [134, 141]. In contrast, in another observational study of 60 patients, the average number of transfused units was 5.2; however, these patients underwent preoperative tumor embolization [140]. It is important to note that the highest number of PRBCs transfused was in patients undergoing hemisacrectomies, with $75 \%$ of them receiving 10 or more units of blood [134, 139]. Thus, massive blood transfusions are common in patients undergoing sacrectomies.

Collectively, resection of spine and sacral tumors presents a formidable challenge to the anesthesia team. As massive bleeding and blood transfusions are extremely common, it would be prudent for anesthesiologists to discuss different perioperative interventions and strategies to reduce bleeding with the surgical team.

\section{Conclusion}

Patients undergoing major oncological surgery are at risk for severe bleeding and massive blood transfusion due to tumor characteristics, preoperative chemoradiation, anatomic features of the surgical area (vascular proximity), complexity of resection, duration of surgery, perioperative hypothermia, metabolic derangements, and intraoperative dilutional coagulopathy (blood transfusions and fluid administration). It is therefore crucial for the anesthesia team to have a clear understanding of all those factors and to work closely with a meticulous, efficient, and experienced surgical team to delineate perioperative interventions (tumor embolization, operative staging, and/or pharmacological interventions) targeted to minimize perioperative blood loss (Table 2).

Unfortunately, the current literature review is unclear about the exact incidence of massive blood transfusions in major oncological surgery. Furthermore, there may a bias toward underreporting due to lack of clear definitions of the "perioperative period" in this context and, perhaps, disinterest in the medical community on this topic.

The relationship between immune competence during the perioperative period and recurrence-free survival after a curative resection is becoming a topic of interest. It is well known that allogeneic transfusions induce immune suppression and are an independent predictor of morbidity and mortality [142-144]. The effect of "anesthetic techniques and perioperative management" on positively influencing the balance between inflammation and immune competence is an intriguing avenue for future study. Thus, we urge perioperative clinicians and researchers to start reporting data on massive blood transfusions and to study its impact on clinical outcomes in patients undergoing major oncological surgery.

\section{References}

[1] M. W. Buchler, M. Wagner, B. M. Schmied et al., "Changes in morbidity after pancreatic resection: toward the end of completion pancreatectomy," Archives of Surgery, vol. 138, no. 12, pp. 1310-1315, 2003.

[2] J. H. Balcom, D. W. Rattner, A. L. Warshaw, Y. Chang, and C. Fernandez-Del Castillo, "Ten-year experience with 733 pancreatic resections: changing indications, older patients, and decreasing length of hospitalization," Archives of Surgery, vol. 136, no. 4, pp. 391-398, 2001.

[3] R. M. Merion, "Current status and future of liver transplantation," Seminars in Liver Disease, vol. 30, no. 4, pp. 411-421, 2010.

[4] M. W. Saif, N. Makrilia, A. Zalonis, M. Merikas, and K. Syrigos, "Gastric cancer in the elderly: an overview," European Journal of Surgical Oncology, vol. 36, pp. 709-717, 2010.

[5] G. P. Copeland, D. Jones, and M. Walters, "POSSUM: a scoring system for surgical audit," British Journal of Surgery, vol. 78, no. 3, pp. 355-360, 1991.

[6] C. R. Boyd, M. A. Tolson, and W. S. Copes, "Evaluating trauma care: the TRISS method. Trauma Score and the Injury Severity Score," The Journal of Trauma, vol. 27, pp. 370-378, 1987.

[7] D. Amar, F. M. Grant, H. Zhang, P. J. Boland, D. H. Leung, and J. A. Healey, "Antifibrinolytic therapy and perioperative blood loss in cancer patients undergoing major orthopedic surgery," Anesthesiology, vol. 98, no. 2, pp. 337-342, 2003.

[8] T. O'Keeffe, M. Refaai, K. Tchorz, J. E. Forestner, and R. Sarode, "A massive transfusion protocol to decrease blood component use and costs," Archives of Surgery, vol. 143, no. 7, pp. 686-690, 2008. 
[9] R. Schmidt, G. Rupp-Heim, F. Dammann, C. Ulrich, and J. Nothwang, "Surgical therapy of vertebral metastases. Are there predictive parameters for intraoperative excessive blood loss despite preoperative embolization?” Tumori, vol. 97, no. 1, pp. 66-73, 2011.

[10] O. N. Gottfried, P. E. Schloesser, M. H. Schmidt, and E. A. Stevens, "Embolization of metastatic spinal tumors," Neurosurgery Clinics of North America, vol. 15, no. 4, pp. 391399, 2004.

[11] X. Capdevila, Y. Calvet, P. Biboulet, C. Biron, J. Rubenovitch, and F. D'Athls, "Aprotinin decreases blood loss and homologous transfusions in patients undergoing major orthopedic surgery," Anesthesiology, vol. 88, no. 1, pp. 50-57, 1998.

[12] R. M. Jones, C. E. Moulton, and K. J. Hardy, "Central venous pressure and its effect on blood loss during liver resection," British Journal of Surgery, vol. 85, no. 8, pp. 1058-1060, 1998.

[13] K. S. Gurusamy, T. Pissanou, H. Pikhart, J. Vaughan, A. K. Burroughs, and B. R. Davidson, "Methods to decrease blood loss and transfusion requirements for liver transplantation," Cochrane Database of Systematic Reviews, vol. 12, article CD009052, 2011.

[14] C. C. Wu, W. M. Ho, S. B. Cheng et al., "Perioperative parenteral tranexamic acid in liver tumor resection: a prospective randomized trial toward "blood transfusion"-free hepatectomy," Annals of Surgery, vol. 243, no. 2, pp. 173-180, 2006.

[15] M. Marietta, L. Facchini, P. Pedrazzi, S. Busani, and G. Torelli, "Pathophysiology of Bleeding in Surgery," Transplantation Proceedings, vol. 38, no. 3, pp. 812-814, 2006.

[16] S. Noble and J. Pasi, "Epidemiology and pathophysiology of cancer-associated thrombosis," British Journal of Cancer, vol. 102, no. 1, pp. S2-S9, 2010.

[17] M. N. Levine and A. Y. Y. Lee, "Treatment of venous thrombosis in the cancer patient," Acta Haematologica, vol. 106, no. $1-2$, pp. 81-87, 2001.

[18] S. Lison, G. Weiss, M. Spannagl, and B. Heindl, "Postoperative changes in procoagulant factors after major surgery," Blood Coagulation and Fibrinolysis, vol. 22, no. 3, pp. 190196, 2011.

[19] M. Kohli, V. Kaushal, and P. Mehta, "Role of coagulation and fibrinolytic system in prostate cancer," Seminars in Thrombosis and Hemostasis, vol. 29, no. 3, pp. 301-308, 2003.

[20] M. Nyska, B. Klin, and J. Y. Margulies, "Disseminated intravascular coagulopathy in patients with cancer undergoing operation for pathological fractures of the hip," International Orthopaedics, vol. 11, no. 3, pp. 179-181, 1987.

[21] W. R. Jarnagin, M. Gonen, Y. Fong et al., "Improvement in perioperative outcome after hepatic resection: analysis of 1,803 consecutive cases over the past decade," Annals of Surgery, vol. 236, no. 4, pp. 397-407, 2002.

[22] J. Valent and C. A. Schiffer, "Thrombocytopenia and platelet transfusions in patients with cancer," Cancer Treatment and Research, vol. 157, pp. 251-265, 2011.

[23] W. Z. Martini, D. L. Chinkes, A. E. Pusateri et al., "Acute changes in fibrinogen metabolism and coagulation after hemorrhage in pigs," American Journal of Physiology, vol. 289, no. 5, pp. E930-E934, 2005.

[24] W. Z. Martini, D. L. Chinkes, J. Sondeen, and M. A. Dubick, "Effects of hemorrhage and lactated Ringer's resuscitation on coagulation and fibrinogen metabolism in swine," Shock, vol. 26, no. 4, pp. 396-401, 2006.

[25] T. Kooistra, Y. Schrauwen, J. Arts, and J. J. Emeis, "Regulation of endothelial cell t-PA synthesis and release," International Journal of Hematology, vol. 59, no. 4, pp. 233-255, 1994.
[26] H. M. O'Brodovich, M. Andrew, G. W. Gray, and G. Coates, "Hypoxia alters blood coagulation during acute decompression in humans," Journal of Applied Physiology Respiratory Environmental and Exercise Physiology, vol. 56, no. 3, pp. 666670, 1984.

[27] J. Schneiderman, R. Adar, and N. Savion, "Changes in plasmatic tissue-type plasminogen activator and plasminogen activator inhibitor activity during acute arterial occlusion associated with severe ischemia," Thrombosis Research, vol. 62, no. 5, pp. 401-408, 1991.

[28] A. A. Hanke, S. Maschler, H. Schochl et al., "In vitro impairment of whole blood coagulation and platelet function by hypertonic saline hydroxyethyl starch," Scandinavian Journal of Trauma, Resuscitation and Emergency Medicine, vol. 19, p. $12,2011$.

[29] W. Z. Martini, "Coagulopathy by hypothermia and acidosis: mechanisms of thrombin generation and fibrinogen availability," The Journal of trauma, vol. 67, no. 1, pp. 202-209, 2009.

[30] M. Lynn, I. Jeroukhimov, Y. Klein, and U. Martinowitz, "Updates in the management of severe coagulopathy in trauma patients," Intensive Care Medicine, vol. 28, no. 2, supplemnt, pp. S241-S247, 2002.

[31] A. Jemal, R. Siegel, E. Ward, Y. Hao, J. Xu, and M. J. Thun, "Cancer statistics, 2009," CA Cancer Journal for Clinicians, vol. 59, no. 4, pp. 225-249, 2009.

[32] M. Jibiki, T. Iwai, Y. Inoue et al., "Surgical strategy for treating renal cell carcinoma with thrombus extending into the inferior vena cava," Journal of Vascular Surgery, vol. 39, pp. 829-835, 2004.

[33] J. C. Nesbitt, E. R. Soltero, C. P. N. Dinney et al., "Surgical management of renal cell carcinoma with inferior vena cava tumor thrombus," Annals of Thoracic Surgery, vol. 63, no. 6, pp. 1592-1600, 1997.

[34] B. Chiappini, C. Savini, G. Marinelli et al., "Cavoatrial tumor thrombus: single-stage surgical approach with profound hypothermia and circulatory arrest, including a review of the literature," Journal of Thoracic and Cardiovascular Surgery, vol. 124, no. 4, pp. 684-688, 2002.

[35] C. Wotkowicz, M. F. Wszolek, and J. A. Libertino, "Resection of renal tumors invading the vena cava," Urologic Clinics of North America, vol. 35, no. 4, pp. 657-671, 2008.

[36] M. Yezhelyev, V. Master, V. Egnatashvili, and D. A. Kooby, "Combined nephrectomy and major hepatectomy: indications, outcomes, and recommendations," Journal of the American College of Surgeons, vol. 208, no. 3, pp. 410-418, 2009.

[37] V. S. Subramanian, A. J. Stephenson, D. A. Goldfarb, A. F. Fergany, A. C. Novick, and V. Krishnamurthi, "Utility of preoperative renal artery embolization for management of renal tumors with inferior vena caval thrombi," Urology, vol. 74, no. 1, pp. 154-159, 2009.

[38] M. Crocker, G. James, A. Ibrahim, N. Thomas, and B. Chitnavis, "Posterior approach vertebrectomy in the thoracolumbar spine with expandable cage reconstruction: Indications and techniques based on eight cases," British Journal of Neurosurgery, vol. 22, no. 2, pp. 235-240, 2008.

[39] J. C. Wang, P. Boland, N. Mitra et al., "Single-stage posterolateral transpedicular approach for resection of epidural metastatic spine tumors involving the vertebral body with circumferential reconstruction: results in 140 patients. Invited submission from the Joint Section Meeting on Disorders of the Spine and Peripheral Nerves, March 2004," Journal of Neurosurgery, vol. 1, no. 3, pp. 287-298, 2004. 
[40] F. H. Shen, I. Marks, C. Shaffrey, J. Ouellet, and V. Arlet, "The use of an expandable cage for corpectomy reconstruction of vertebral body tumors through a posterior extracavitary approach: a multicenter consecutive case series of prospectively followed patients," The Spine Journal, vol. 8, pp. 329339, 2008.

[41] R. Xu, G. L. Garcés-Ambrossi, M. J. McGirt et al., "Thoracic vertebrectomy and spinal reconstruction via anterior, posterior, or combined approaches: clinical outcomes in 91 consecutive patients with metastatic spinal tumors-clinical article," Journal of Neurosurgery, vol. 11, no. 3, pp. 272-284, 2009.

[42] F. C. Vinas, P. K. King, H. Holdener, S. Dulchavsky, and F. G. Diaz, "Outcome and complications of reconstruction of the thoracolumbar spine for vertebral tumours," Journal of Clinical Neuroscience, vol. 6, pp. 467-473, 1999.

[43] M. Eleraky, I. Papanastassiou, N. D. Tran, E. Dakwar, and F. D. Vrionis, "Comparison of polymethylmethacrylate versus expandable cage in anterior vertebral column reconstruction after posterior extracavitary corpectomy in lumbar and thoraco-lumbar metastatic spine tumors," European Spine Journal, vol. 20, pp. 1363-1370, 2011.

[44] D. R. Fourney, L. D. Rhines, S. J. Hentschel et al., "En bloc resection of primary sacral tumors: classification of surgical approaches and outcome," Journal of Neurosurgery, vol. 3, no. 2, pp. 111-122, 2005.

[45] X. Tang, W. Guo, R. Yang, S. Tang, and T. Ji, "Risk factors for blood loss during sacral tumor resection," Clinical Orthopaedics and Related Research, vol. 467, no. 6, pp. 1599-1604, 2009.

[46] D. Li, W. Guo, X. Tang, T. Ji, and Y. Zhang, "Surgical classification of different types of en bloc resection for primary malignant sacral tumors," European Spine Journal, vol. 20, pp. 2275-2281, 2011.

[47] G. C. Guimarães, G. Baiocchi, F. O. Ferreira et al., "Palliative pelvic exenteration for patients with gynecological malignancies," Archives of Gynecology and Obstetrics, vol. 283, no. 5, pp. 1107-1112, 2011.

[48] K. A. McLean, W. Zhang, R. F. Dunsmoor-Su et al., "Pelvic exenteration in the age of modern chemoradiation," Gynecologic Oncology, vol. 121, no. 1, pp. 131-134, 2011.

[49] F. Khoury-Collado, M. H. Einstein, B. H. Bochner et al., "Pelvic exenteration with curative intent for recurrent uterine malignancies," Gynecologic oncology, vol. 124, no. 1, pp. 4247, 2011.

[50] D. M. Forner and B. Lampe, "Exenteration in the treatment of Stage III/IV vulvar cancer," Gynecologic Oncology, vol. 124, no. 1, pp. 87-91, 2012.

[51] D. Radak, P. Milojevic, S. Babic et al., "Renal tumor with tumor thrombus in inferior vena cava and right atrium: the report of five cases with long-term follow-up," International Urology and Nephrology, vol. 43, pp. 1033-1038, 2011.

[52] J. Parra, S. J. Drouin, V. Hupertan, E. Comperat, M. O. Bitker, and M. Roupret, "Oncological outcomes in patients undergoing radical nephrectomy and vena cava thrombectomy for renal cell carcinoma with venous extension: a single-centre experience," European Journal of Surgical Oncology, vol. 37, pp. 422-428, 2011.

[53] B. T. Helfand, N. D. Smith, J. M. Kozlowski, and M. K. Eskandari, "Vena cava thrombectomy and primary repair after radical nephrectomy for renal cell carcinoma: Single-center experience," Annals of Vascular Surgery, vol. 25, no. 1, pp. 3943, 2011.
[54] S. Delis, C. Dervenis, D. Lytras, C. Avgerinos, M. Soloway, and G. Ciancio, "Liver transplantation techniques with preservation of the natural venovenous bypass: effect on surgical resection of renal cell carcinoma invading the inferior vena cava," World Journal of Surgery, vol. 28, no. 6, pp. 614619, 2004.

[55] L. Zini, M. Koussa, S. Haulon et al., "Results of endoluminal occlusion of the inferior vena cava during radical nephrectomy and thrombectomy," European Urology, vol. 54, no. 4, pp. 778-784, 2008.

[56] A. L. Young, R. Adair, K. R. Prasad, G. J. Toogood, and J. P. Lodge, "Hepatocellular carcinoma within a noncirrhotic, nonfibrotic, seronegative liver: surgical approaches and outcomes," Journal of the American College of Surgeons, vol. 214, no. 2, pp. 174-183, 2011.

[57] T. Yang, J. Zhang, J. H. Lu, G. S. Yang, M. C. Wu, and W. F. Yu, "Risk factors influencing postoperative outcomes of major hepatic resection of hepatocellular carcinoma for patients with underlying liver diseases," World Journal of Surgery, vol. 35, pp. 2073-2082, 2011.

[58] Y. Tomimaru, H. Wada, S. Marubashi et al., "Fresh frozen plasma transfusion does not affect outcomes following hepatic resection for hepatocellular carcinoma," World Journal of Gastroenterology, vol. 16, no. 44, pp. 5603-5610, 2010.

[59] L. Vigano, S. A. Jaffary, A. Ferrero, N. Russolillo, S. Langella, and L. Capussotti, "Liver resection without pedicle clamping: feasibility and need for "salvage clamping". Looking for the right clamping policy. Analysis of 512 consecutive resections," Journal of Gastrointestinal Surgery, vol. 15, pp. 1820 1828, 2011.

[60] M. A. Allard, F. Dondero, D. Sommacale, S. Dokmak, J. Belghiti, and O. Farges, "Liver packing during elective surgery: an option that can be considered," World Journal of Surgery, vol. 35, pp. 2493-2498, 2011.

[61] A. W. Hemming, J. F. Magliocca, S. Fujita et al., "Combined resection of the liver and pancreas for malignancy," Journal of the American College of Surgeons, vol. 210, no. 5, pp. 808-814, 2010.

[62] C. M. Burdelski, M. Reeh, D. Bogoevski et al., "Multivisceral resections in pancreatic cancer: identification of risk factors," World Journal of Surgery, vol. 35, pp. 2756-2763, 2011.

[63] M. de Perrot, K. McRae, M. Anraku et al., "Risk factors for major complications after extrapleural pneumonectomy for malignant pleural mesothelioma," Annals of Thoracic Surgery, vol. 85, no. 4, pp. 1206-1210, 2008.

[64] P. H. Norman, P. F. Thall, R. V. Purugganan et al., "A possible association between aprotinin and improved survival after radical surgery for mesothelioma," Cancer, vol. 115, no. 4, pp. 833-841, 2009.

[65] F. Bakaeen, D. Rice, A. M. Correa et al., "Use of aprotinin in extrapleural pneumonectomy: effect on hemostasis and incidence of complications," Annals of Thoracic Surgery, vol. 84, no. 3, pp. 982-986, 2007.

[66] C. Wotkowicz, J. A. Libertino, A. Sorcini, and A. Mourtzinos, "Management of renal cell carcinoma with vena cava and atrial thrombus: minimal access vs median sternotomy with circulatory arrest," British Journal of Urology International, vol. 98, no. 2, pp. 289-297, 2006.

[67] J. C. Wheat, W. W. Roberts, B. K. Hollenbeck, J. S. Wolf, and A. Z. Weizer, "Complications of laparoscopic partial nephrectomy," Urologic Oncology. In press.

[68] M. Gallucci, D. Borzomati, G. Flammia et al., "Liver harvesting surgical technique for the treatment of retro-hepatic caval 
thrombosis concomitant to renal cell carcinoma: perioperative and long-term results in 15 patients without mortality," European Urology, vol. 45, no. 2, pp. 194-202, 2004.

[69] J. R. Stewart, J. A. Carey, W. S. McDougal, W. H. Merrill, M. O. Koch, and H. W. Bender, "Cavoatrial tumor thrombectomy using cardiopulmonary bypass without circulatory arrest," Annals of Thoracic Surgery, vol. 51, no. 5, pp. 717$722,1991$.

[70] S. E. Langenburg, L. H. Blackbourne, J. W. Sperling et al., "Management of renal tumors involving the inferior vena cava," Journal of Vascular Surgery, vol. 20, pp. 385-388, 1994.

[71] M. G. Kaag, C. Toyen, P. Russo et al., "Radical nephrectomy with vena caval thrombectomy: a contemporary experience," British Journal of Urology International, vol. 107, no. 9, pp. 1386-1393, 2011.

[72] D. J. Sugarbaker, M. T. Jaklitsch, R. Bueno et al., "Prevention, early detection, and management of complications after 328 consecutive extrapleural pneumonectomies," Journal of Thoracic and Cardiovascular Surgery, vol. 128, no. 1, pp. 138146, 2004.

[73] T. Aziz, A. Jilaihawi, and D. Prakash, "The management of malignant pleural mesothelioma; single centre experience in 10 years," European Journal of Cardio-thoracic Surgery, vol. 22, no. 2, pp. 298-305, 2002.

[74] V. W. Rusch, K. Rosenzweig, E. Venkatraman et al., "A phase II trial of surgical resection and adjuvant highdose hemithoracic radiation for malignant pleural mesothelioma," Journal of Thoracic and Cardiovascular Surgery, vol. 122, no. 4, pp. 788-795, 2001.

[75] P. A. Chretien and P. H. Sugarbaker, "Surgical technique of hemipelvectomy in the lateral position," Surgery, vol. 90, no. 5, pp. 900-909, 1981.

[76] J. P. Apffelstaedt, D. L. Driscoll, J. E. Spellman, A. F. Velez, J. F. Gibbs, and C. P. Karakousis, "Complications and outcome of external hemipelvectomy in the management of pelvic tumors," Annals of Surgical Oncology, vol. 3, pp. 304-309, 1996.

[77] A. Senchenkov, S. L. Moran, P. M. Petty et al., "Predictors of complications and outcomes of external hemipelvectomy wounds: account of 160 consecutive cases," Annals of Surgical Oncology, vol. 15, no. 1, pp. 355-363, 2008.

[78] N. L. Higinbotham, R. C. Marcove, and P. Casson, "Hemipelvectomy: a clinical study of 100 cases with five year followup on 60 patients," Surgery, vol. 59, no. 5, pp. 706-708, 1966.

[79] T. R. Miller, "100 Cases of hemipelvectomy: a personal experience," Surgical Clinics of North America, vol. 54, no. 4, pp. 905-913, 1974.

[80] T. W. Prewitt, H. R. Alexander, and W. F. Sindelar, "Hemipelvectomy for soft tissue sarcoma: clinical results in fifty-three patients," Surgical Oncology, vol. 4, no. 5, pp. 261269, 1995.

[81] R. M. J. M. Butzelaar and J. G. Fortner, "Results of hemipelvectomy for soft tissue sarcoma," Netherlands Journal of Surgery, vol. 33, no. 2, pp. 79-82, 1981.

[82] M. B. Nielsen, P. Rasmussen, K. Johnny, and S. Laurberg, "Preliminary experience with external hemipelvectomy for locally advanced and recurrent pelvic carcinoma," Colorectal Disease, vol. 14, no. 2, pp. 152-156, 2012.

[83] C. R. Baliski, N. S. Schachar, J. G. McKinnon, G. C. Stuart, and W. J. Temple, "Hemipelvectomy: a changing perspective for a rare procedure," Canadian Journal of Surgery, vol. 47, no. 2, pp. 99-103, 2004.

[84] M. E. Pring, K. L. Weber, K. K. Unni, and F. H. Sim, "Chondrosarcoma of the pelvis: a review of sixty-four cases,"
Journal of Bone and Joint Surgery A, vol. 83, no. 11, pp. 163016342, 2001.

[85] C. P. Karakousis, L. J. Emrich, and D. L. Driscoll, "Variants of hemipelvectomy and their complications," American Journal of Surgery, vol. 158, no. 5, pp. 404-408, 1989.

[86] W. Sun, J. Li, Q. Li, G. Li, and Z. Cai, "Clinical effectiveness of hemipelvic reconstruction using computer-aided custommade prostheses after resection of malignant pelvic tumors," Journal of Arthroplasty, vol. 26, pp. 1508-1513, 2011.

[87] R. D. Lackman, E. A. Crawford, H. S. Hosalkar, J. J. King, and C. M. Ogilvie, "Internal hemipelvectomy for pelvic sarcomas using a t-incision surgical approach," Clinical Orthopaedics and Related Research, vol. 467, no. 10, pp. 2677-2684, 2009.

[88] J. P. Apffelstaedt, D. L. Driscoll, and C. P. Karakousis, "Partial and complete internal hemipelvectomy: complications and long-term follow-up," Journal of the American College of Surgeons, vol. 181, no. 1, pp. 43-48, 1995.

[89] F. R. Eilber, T. T. Grant, D. Sakai, and D. L. Morton, "Internal hemipelvectomy-excision of the hemipelvis with limb preservation. An alternative to hemipelvectomy," Cancer, vol. 43, no. 3, pp. 806-809, 1979.

[90] R. Molnar, G. Emery, and P. F. M. Choong, "Anaesthesia for hemipelvectomy-a series of 49 cases," Anaesthesia and Intensive Care, vol. 35, no. 4, pp. 536-543, 2007.

[91] M. I. O'Connor and F. H. Sim, "Salvage of the limb in the treatment of malignant pelvic tumors," Journal of Bone and Joint Surgery A, vol. 71, no. 4, pp. 481-494, 1989.

[92] T. M. Pawlik, J. M. Skibber, and M. A. Rodriguez-Bigas, "Pelvic exenteration for advanced pelvic malignancies," Annals of Surgical Oncology, vol. 13, no. 5, pp. 612-623, 2006.

[93] K. K. S. Austin and M. J. Solomon, "Pelvic exenteration with en bloc iliac vessel resection for lateral pelvic wall involvement," Diseases of the Colon and Rectum, vol. 52, no. 7, pp. 1223-1233, 2009.

[94] J. H. W. de Wilt, D. H. J. van Leeuwen, A. Logmans et al., "Pelvic exenteration for primary and recurrent gynaecological malignancies," European Journal of Obstetrics Gynecology and Reproductive Biology, vol. 134, no. 2, pp. 243-248, 2007.

[95] V. Lohsiriwat and D. Lohsiriwat, "Comparison of immediate surgical outcomes between posterior pelvic exenteration and standard resection for primary rectal cancer: a matched casecontrol study," World Journal of Gastroenterology, vol. 14, no. 15, pp. 2414-2417, 2008.

[96] A. Maggioni, G. Roviglione, F. Landoni et al., "Pelvic exenteration: ten-year experience at the European Institute of Oncology in Milan," Gynecologic Oncology, vol. 114, no. 1, pp. 64-68, 2009.

[97] E. Zoucas, S. Frederiksen, M. L. Lydrup, W. Månsson, P. Gustafson, and P. Alberius, "Pelvic exenteration for advanced and recurrent malignancy," World Journal of Surgery, vol. 34, pp. 2177-2184, 2010.

[98] M. Nielsen, P. Rasmussen, J. Lindegaard, and S. A. Laurberg, "10-year experience of total pelvic exenteration for primary advanced and locally recurrent rectal cancer based on a prospective database," Colorectal Disease. In press.

[99] W. Y. Lau, E. C. H. Lai, and S. H. Y. Lau, "Methods of vascular control technique during liver resection: a comprehensive review," Hepatobiliary and Pancreatic Diseases International, vol. 9, no. 5, pp. 473-481, 2010.

[100] T. A. Aloia, B. N. Fahy, C. P. Fischer et al., "Predicting poor outcome following hepatectomy: analysis of 2313 hepatectomies in the NSQIP database," HPB, vol. 11, pp. 510-515, 2009. 
[101] V. Resende, J. B. Rezende-Neto, J. S. Fernandes, and J. R. Cunha-Melo, "Assessment of morbidity and mortality after hepatic resections," Revista do Colegio Brasileiro de Cirurgioes, vol. 38, pp. 323-326, 2011.

[102] T. S. Helling, B. Blondeau, and B. J. Wittek, "Perioperative factors and outcome associated with massive blood loss during major liver resections," $H P B$, vol. 6, pp. 181-185, 2004.

[103] S. C. Katz, J. Shia, K. H. Liau et al., "Operative blood loss independently predicts recurrence and survival after resection of hepatocellular carcinoma," Annals of Surgery, vol. 249, no. 4, pp. 617-623, 2009.

[104] H. Ekberg, K. G. Tranberg, and R. Andersson, "Major liver resection: perioperative course and management," Surgery, vol. 100, no. 1, pp. 1-8, 1986.

[105] Y. Ishizaki, J. Yoshimoto, K. Miwa, H. Sugo, and S. Kawasaki, "Safety of prolonged intermittent Pringle maneuver during hepatic resection," Archives of Surgery, vol. 141, no. 7, pp. 649-653, 2006.

[106] J. Emond, M. E. Wachs, J. F. Renz et al., "Total vascular exclusion for major hepatectomy in patients with abnormal liver parenchyma," Archives of Surgery, vol. 130, no. 8, pp. 824-831, 1995.

[107] Y. Sakamoto, J. Yamamoto, N. Kokudo et al., "Bloodless liver resection using the monopolar floating ball plus ligasure diathermy: preliminary results of 16 liver resections," World Journal of Surgery, vol. 28, no. 2, pp. 166-172, 2004.

[108] C. G. Ker, J. S. Chen, K. K. Kuo et al., "Liver surgery for hepatocellular carcinoma: laparoscopic versus open approach," International Journal of Hepatology, vol. 2011, Article ID 596792, 6 pages, 2011.

[109] S. Y. Fu, W. Y. Lau, G. G. Li et al., "A prospective randomized controlled trial to compare Pringle maneuver, hemihepatic vascular inflow occlusion, and main portal vein inflow occlusion in partial hepatectomy," American Journal of Surgery, vol. 201, no. 1, pp. 62-69, 2011.

[110] J. Figueras, L. Llado, D. Ruiz et al., "Complete versus selective portal triad clamping for minor liver resections: a prospective randomized trial," Annals of Surgery, vol. 241, no. 4, pp. 582590, 2005.

[111] M. Rees, G. Plant, J. Wells, and S. Bygrave, "One hundred and fifty hepatic resections: evolution of technique towards bloodless surgery," British Journal of Surgery, vol. 83, no. 11, pp. 1526-1529, 1996.

[112] C. Lentschener, D. Benhamou, F. J. Mercier et al., "Aprotinin reduces blood loss in patients undergoing elective liver resection," Anesthesia and Analgesia, vol. 84, no. 4, pp. 875881, 1997.

[113] D. T. Mangano, I. C. Tudor, and C. Dietzel, "The risk associated with aprotinin in cardiac surgery," New England Journal of Medicine, vol. 354, no. 4, pp. 353-365, 2006.

[114] I. Vassiliou, N. Arkadopoulos, V. Stafyla et al., "The introduction of a simple maneuver to reduce the risk of postoperative bleeding after major hepatectomies," Journal of HepatoBiliary-Pancreatic Surgery, vol. 16, no. 4, pp. 552-556, 2009.

[115] R. C. G. Martin, W. R. Jarnagin, Y. Fong, P. Biernacki, L. H. Blumgart, and R. P. DeMatteo, "The use of fresh frozen plasma after major hepatic resection for colorectal metastasis: is there a standard for transfusion?" Journal of the American College of Surgeons, vol. 196, no. 3, pp. 402-409, 2003.

[116] E. F. Yekebas, D. Bogoevski, G. Cataldegirmen et al., "En bloc vascular resection for locally advanced pancreatic malignancies infiltrating major blood vessels: perioperative outcome and long-term survival in 136 patients," Annals of Surgery, vol. 247, no. 2, pp. 300-309, 2008.

[117] J. E. Mullinax, J. S. Zager, and R. J. Gonzalez, "Current diagnosis and management of retroperitoneal sarcoma," Cancer Control, vol. 18, pp. 177-1787, 2011.

[118] M. B. Farnell, R. K. Pearson, M. G. Sarr et al., "A prospective randomized trial comparing standard pancreatoduodenectomy with pancreatoduodenectomy with extended lymphadenectomy in resectable pancreatic head adenocarcinoma," Surgery, vol. 138, no. 4, pp. 618-630, 2005.

[119] H. Amano, F. Miura, N. Toyota et al., "Pancreatectomy with reconstruction of the right and left hepatic arteries for locally advanced pancreatic cancer," Journal of HepatoBiliary-Pancreatic Surgery, vol. 16, no. 6, pp. 777-780, 2009.

[120] P. Toomey, J. Hernandez, C. Morton et al., "Resection of portovenous structures to obtain microscopically negative margins during pancreaticoduodenectomy for pancreatic adenocarcinoma is worthwhile," American Surgeon, vol. 75, no. 9, pp. 804-809, 2009.

[121] A. McKay, F. R. Sutherland, O. F. Bathe, and E. Dixon, "Morbidity and mortality following multivisceral resections in complex hepatic and pancreatic surgery," Journal of Gastrointestinal Surgery, vol. 12, pp. 86-90, 2008.

[122] M. Crocker and B. Chitnavis, "Total thoracic vertebrectomy with anterior and posterior column reconstruction via single posterior approach," British Journal of Neurosurgery, vol. 21, no. 1, pp. 28-31, 2007.

[123] S. N. Khan and R. Donthineni, "Surgical management of metastatic spine tumors," Orthopedic Clinics of North America, vol. 37, no. 1, pp. 99-104, 2006.

[124] H. Deutsch, T. Boco, and J. Lobel, "Minimally invasive transpedicular vertebrectomy for metastatic disease to the thoracic spine," Journal of Spinal Disorders and Techniques, vol. 21, no. 2, pp. 101-105, 2008.

[125] P. J. Holman, D. Suki, I. McCutcheon, J. P. Wolinsky, L. D. Rhines, and Z. L. Gokaslan, "Surgical management of metastatic disease of the lumbar spine: experience with 139 patients," Journal of Neurosurgery, vol. 2, no. 5, pp. 550-563, 2005.

[126] G. J. King, J. P. Kostuik, R. J. McBroom, and W. Richardson, "Surgical management of metastatic renal carcinoma of the spine," Spine, vol. 16, no. 3, pp. 265-271, 1991.

[127] T. Lorincz, J. Tímár, and M. Szendroi, "Alterations of microvascular density in bone metastases of adenocarcinomas," Pathology and Oncology Research, vol. 10, no. 3, pp. 149-153, 2004.

[128] R. P. Dutton, "Controlled hypotension for spinal surgery," European Spine Journal, vol. 13, Supplement 1, pp. S66-S71, 2004.

[129] M. Veien, J. V. Sørensen, F. Madsen, and P. Juelsgaard, "Tranexamic acid given intraoperatively reduces blood loss after total knee replacement: a randomized, controlled study," Acta Anaesthesiologica Scandinavica, vol. 46, no. 10, pp. 1206-1211, 2002.

[130] P. M. Bokesch, G. Szabo, R. Wojdyga et al., "A phase 2 prospective, randomized, double-blind trial comparing the effects of tranexamic acid with ecallantide on blood loss from high-risk cardiac surgery with cardiopulmonary bypass (CONSERV-2 Trial)," Journal of Thoracic and Cardiovascular Surgery. In press.

[131] A. A. Dhawale, S. A. Shah, P. D. Sponseller et al., "Are antifibrinolytics helpful in decreasing blood loss and transfusions during spinal fusion surgery in children with cerebral palsy scoliosis?" Spine, vol. 37, no. 9, pp. E549-E555, 2012. 
[132] D. A. Bednar, V. A. Bednar, A. Chaudhary, and F. Farroukhyar, "Tranexamic acid for hemostasis in the surgical treatment of metastatic tumors of the spine," Spine, vol. 31, no. 8, pp. 954-957, 2006.

[133] P. Bergh, L. G. Kindblom, B. Gunterberg, F. Remotti, W. Ryd, and J. M. Meis-Kindblom, "Prognostic factors in chordoma of the sacrum and mobile spine: a study of 39 patients," Cancer, vol. 88, pp. 2122-2134, 2000.

[134] M. Sabourin, D. Biau, A. Babinet, V. Dumaine, B. Tomeno, and P. Anract, "Surgical management of pelvic primary bone tumors involving the sacroiliac joint," Orthopaedics and Traumatology, vol. 95, no. 4, pp. 284-292, 2009.

[135] P. Wuisman, O. Lieshout, S. Sugihara, and M. Van Dijk, "Total sacretomy and reconstruction: oncologic and functional outcome," Clinical Orthopaedics and Related Research, no. 381, pp. 192-203, 2000.

[136] C. Devin, P. Y. Chong, G. E. Holt et al., "Level-adjusted perioperative risk of sacral amputations," Journal of Surgical Oncology, vol. 94, no. 3, pp. 203-211, 2006.

[137] X. Tang, W. Guo, R. Yang, S. Tang, and S. Dong, "Use of aortic balloon occlusion to decrease blood loss during sacral tumor resection," The Journal of Bone and Joint Surgery, vol. 92, pp. 1747-1753, 2010.

[138] L. Zhang, Q. Gong, H. Xiao, C. Tu, and J. Liu, "Control of blood loss during sacral surgery by aortic balloon occlusion," Anesthesia and Analgesia, vol. 105, no. 3, pp. 700-703, 2007.

[139] C. Sahakitrungruang, K. Chantra, N. Dusitanond, P. Atittharnsakul, and A. Rojanasakul, "Sacrectomy for primary sacral tumors," Diseases of the Colon and Rectum, vol. 52, no. 5, pp. 913-918, 2009.

[140] H. L. Yang, K. W. Chen, G. L. Wang et al., "Pre-operative transarterial embolization for treatment of primary sacral tumors," Journal of Clinical Neuroscience, vol. 17, pp. 1280$1285,2010$.

[141] R. Ramamurthy, J. C. Bose, V. Muthusamy, M. Natarajan, and D. Kunjithapatham, "Staged sacrectomy-an adaptive approach: clinical article," Journal of Neurosurgery, vol. 11, no. 3, pp. 285-294, 2009.

[142] J. P. Isbister, A. Shander, D. R. Spahn, J. Erhard, S. L. Farmer, and A. Hofmann, "Adverse blood transfusion outcomes: establishing causation," Transfusion Medicine Reviews, vol. 25, no. 2, pp. 89-101, 2011.

[143] D. R. Spahn, A. Shander, A. Hofmann, and M. F. Berman, "More on transfusion and adverse outcome: it's time to change," Anesthesiology, vol. 114, no. 2, pp. 234-236, 2011.

[144] A. Shander, A. Fink, M. Javidroozi et al., "Appropriateness of allogeneic red blood cell transfusion: the international consensus conference on transfusion outcomes," Transfusion Medicine Reviews, vol. 25, no. 3, pp. 232-246, 2011. 


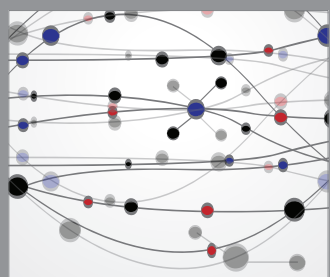

The Scientific World Journal
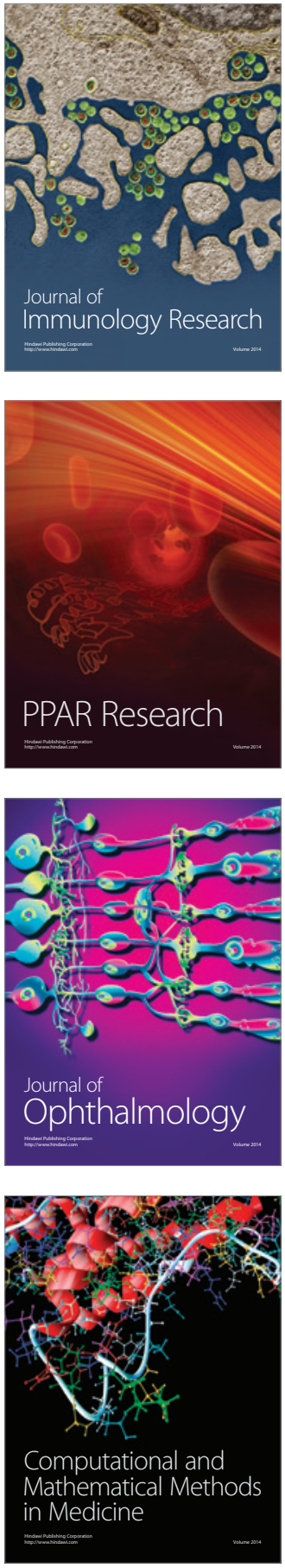



Gastroenterology

Research and Practice


\section{Hindawi}

Submit your manuscripts at

http://www.hindawi.com
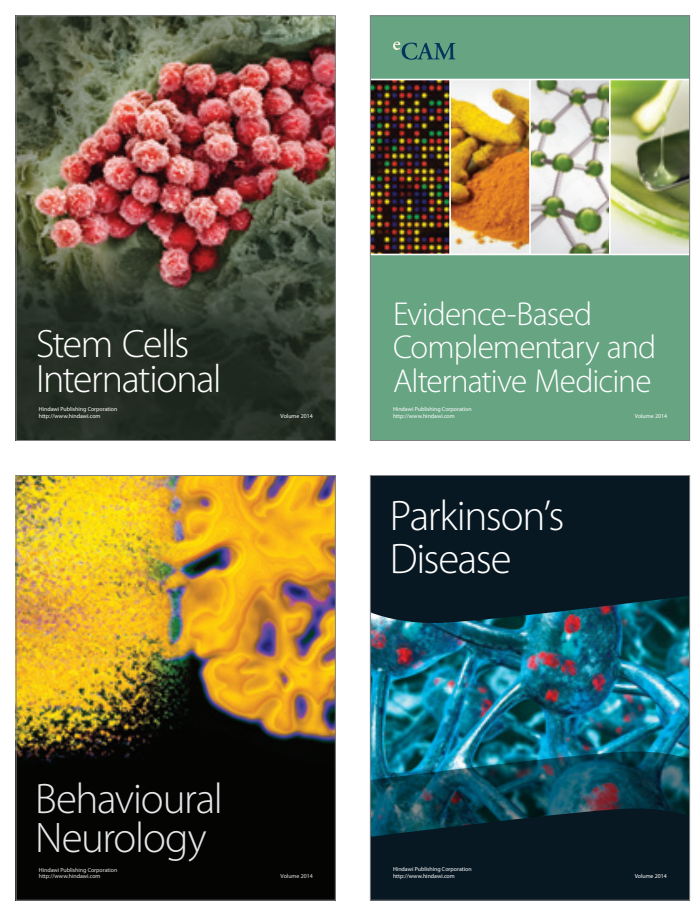

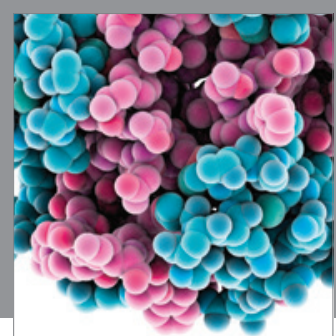

Journal of
Diabetes Research

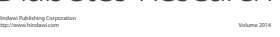

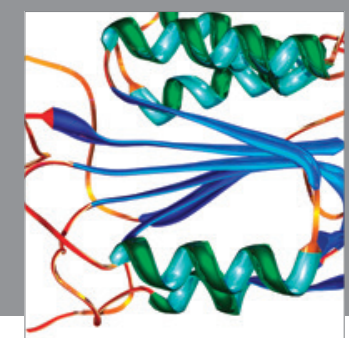

Disease Markers
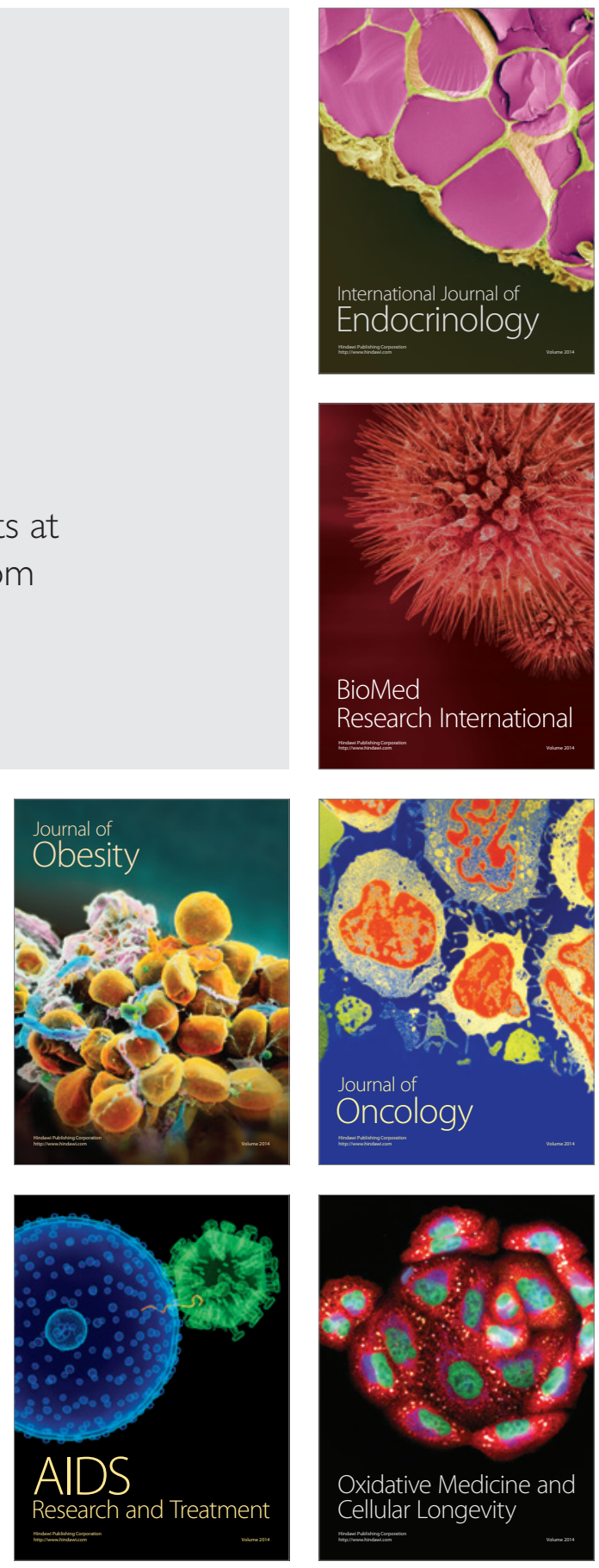